\title{
VARIETAL ROLE IN THE MANAGEMENT OF THE LARGER GRAIN BORER, PROSTEPHANUS TRUNCATUS (HORN) IN S TORED MAIZE
}

\author{
CP Rugumamu \\ Department of Zoology and Wildlife Conservation, University of Dar es Salaam, \\ P.O. Box 35064 Dar es Salaam, Tanzania.wrugu@udsm.ac.tz
}

\begin{abstract}
The study determined the amount of haemolymph vitellogenin (Vg) of the Larger Grain Borer (LGB), Prostephanus truncatus (Horn) vitellogenic females reared on different maize varieties. The varieties were ZM 521, ZM 421, ECAVL1-DLN, WEEVIL A, LOCAL 1 and LOCAL 2. Sodium Dodecyl Sulphate-Polyacrylamide Gel Electrophoresis (SDS - PAGE) was conducted on the insect haemolymph. $F_{1} L G B$ adults from each variety were used to determine Indices of Susceptibility (IS) of the varieties to the insect pest attack. Percentages of Vg from female insects and IS were in the order ZM 521>ZM 421> ECAVL1-DLN>WEEVIL A $>$ LOCAL 1>LOCAL 2. Weight losses of the varieties after $F_{1}$ emergence were recorded. Findings showed that the IS and the weight losses were highest in ZM 521 and lowest in LOCAL 2. ANOVA indicated significant differences in the IS, weight loses and Vg levels of insects among the varieties. IS and Vg were positively correlated. Varying $V g$ levels reflect reproductive capacity of $\mathrm{P}$. truncatus and therefore used to identify resistant maize grains. It is concluded that resistant varieties play a great role in stored maize pest management by reducing LGB populations below economic injury levels (EIL).
\end{abstract}

\section{INTRODUCTION}

Poor storage practices have been cited to be among major causes of food loss in many regions of Tanzania. Losses due to stored pests are currently estimated to be between 35 and $40 \%$ (UNIDO 2004). According to KILIMO/GTZ (1996) crop pest infestations deprive farmers of significant parts of their production yearly. Ravnborg 2004 estimated that $10-40 \%$ of the world's gross agricultural production is damaged by pests. Insect pests cause greater losses of maize crop particularly in storage where it is kept for a relatively longer time for future utilization.

Maize, Zea mays (L.) is an increasingly important cereal crop grown and stored in almost all ecosystems in Sub-Saharan Africa (Abate et al. 2000). It is a staple food and cash crop and various varieties are grown in almost all the regions of Tanzania. The major producing areas include Morogoro, Iringa, Mbeya, Ruvuma and Rukwa regions. Nutritional and physical statuses of maize varieties are reported to contribute to varying levels of their resistance to insect pests attack. These attributes are advocated for consideration in the maize breeding for pest management (Dent 2000).

Principal causes of stored maize crop losses today are insect pest species belonging to various families including, Curculionidae, Bostrichidae, Gelechiidae, Pyralidae, Tenebrionidae. The common pests species are Sitophilus spp.; Sitotroga cerealella (Olivier); Ephestia; Tribolium spp and the Larger Grain Borer (LGB), Prostephanus truncatus (Horn), an alien causing devastating damage to stored maize, (Haines 1999, Borgemeister 2001, Dhliwayo and Pixley 2003, Dhliwayo et al. 2005, Rugumamu 2005). The biology and infestations of the insect pests were reviewed by among others, Hodges et al. (1983), Hill (1987) and Borgemeister (2001).

Storage problems of maize have become more acute because of the great damage caused by the LGB which became established in Tanzania in the early 1980s. The insect feeding habit has incapacitated some rural household storage technologies 
(Rugumamu 2003). This LGB is confirmed as a serious stored grain pest in many African countries including Tanzania. In this regard, an evaluation of effects of some more maize genotypes to this pest shed light on the designing of appropriate pest management strategies in stored maize.

The ensuing losses in stored maize impact negatively the national food security in particular and the economy in general (FAO 1991). It is reported in the National Strategy for Growth and Reduction of Poverty (URT 2005) that poverty remains overwhelming in rural areas where about $87 \%$ of the population live. Initiatives to reduce the maize losses in rural storage systems where livelihoods are based on agriculture will contribute to the reduction in the spread and depth of poverty.

Control of insect pests by some farmers in Tanzania include, application of industrial pesticides such as permethrine; pirimiphosmethyl, an organophosphosphorus (Kilimo/GTZ 1996) but this strategy has had several shortcomings. It was reveal that the use of chemicals not only increases the production costs but also pose health hazards to both producers and consumers and the ecosystem where the pests develop biotypes resistant to the chemicals (Elwells and Maas 1996, Dent 2000). This study propagates the cultivation and storage of more resistant maize varieties to insect infestations and damage as a better management technology to stored products pests.

One of the important characteristics of resistant crop varieties is to lower pest population density and damage symptoms compared to susceptible varieties. This is a very important component of Integrated Pest Management, an approach that combines all economically, technically and ecologically applicable technologies to keep pest populations below those causing economic injury while minimizing unwanted side effects of the applied measures
(Neuenschwander et al. 2003). In many respects as Bhatia (1976) correctly reports, crop breeding for pest resistance is the most ecologically desirable insurance measure to be employed in pest management programmes. The time factor is quite considerable in that a breeding programme is slow to conduct, and the cost may be exorbitant, but the end results could be a very long-term pest control. Indices of susceptibility (IS) and weight losses of crop varieties are among the methods currently used to identify maize varieties which are resistant to insect attack (Bhatia 1976, Dobie 1974).

In this study the determined vitellogenin $(\mathrm{Vg})$ levels in $\mathrm{F}_{1}$ vitellogenic females $P$. truncatus heamolymph reared on different varieties was used to identify resistance of a variety to the insect attack. Vitellogenin is a precursor of yolk components thus its varying amounts in the insects reflect the insect reproductive potential when fed on a maize variety (Hans-Jorg 1993, Kostal 1993, Raikhel and Snigirevskaya 1998). Increasing evidence reveals that in many insects the process of ovarian maturation that contribute most immediately to egg load also respond to variation in host quality (Aluja et al. 2001). This study investigated the varietal role in the management of $\mathrm{P}$. truncates in stored maize.

\section{MATERIALS AND METHODS Maize Samples}

The maize varieties were obtained from Mkambarani village through purchase of local varieties (LOCAL 1 and LOCAL 2) from farmers. The improved varieties namely, ZM 521, ZM 421, ECAVL 1 DLN, WEEVIL A were supplied by agricultural extension staff who cultivated them for various other experiments. Mkambarani was one of the villages which were reported by the regional authority to experience frequent outbreaks of insect pests of stored maize in Morogoro Region. Participatory Rural Appraisal (PRA 1991) approach using focus group discussions 
(FGD) was employed in collecting data on the insect pests and maize varieties.

\section{Investigation of Index of Susceptibility and Weight Loss of the Maize to LGB}

Pure cultures of $P$. truncatus from Ilonga Agricultural Research Institute were used in the determination of vitellogenin levels, indices of susceptibility, weight losses and hence identification of varying resistance of the maize varieties. Adults were introduced in jars with maize (moisture content $11.84 \%$ to $12.75 \%$ ) for egg deposition and were removed after three weeks. The emerging insects were collected daily for seven days (parent stock 1-7 days old). The sexes of the insect were determined according to the method by Shires and McCarthy (1976).

Samples of maize varieties, free of infestation were equilibrated for 7 days at $27^{\circ}-32^{\circ} \mathrm{C}$ and relative humidity of 70 $80 \%$. Insects were conditioned to the maize varieties for one week by infesting eight 30 g samples of each variety with 12 females and 6 males i.e the ratio of $F: M=2: 1$ (Dobie 1974). Six replicates of the surviving insects from each variety were placed in fresh $30 \mathrm{~g}$ samples of the respective varieties contained in ventilated glass bottles. The controls were set. These parent insects are at the beginning of peak oviposition and were removed from test samples after 14 days. Test replicates were kept for 7 days after which the emerged $F_{1}$ were removed, counted and recorded for the determination of vitellogenin levels as well as the calculation of IS of each cultivar according to the formula by Dobie (1974). Weight losses were determined by the, sampleweight method after applying corrections for the percentage moisture changes derived from the controls.

\section{Determination of Vitellogenin Levels in} $P$. truncatus Female Haemolymph

Vitellogenin levels in haemolymph of $\mathrm{F}_{1}$ vitellogenic females of $P$. truncatus one 1 2 weeks old were assessed as an indicator of the insect reproduction potential after attacking a variety of maize and hence weight loss of the stored maize crop. Sodium Dodecyl Sulphate - Polyacrylamide Gel Electrophoresis of haemolymph sampled from aorta of twenty females and males was run in order to determine the separated vitellogenin amounts (Brewer et al.1974). Samples dissolved in Phosphate Buffered Saline, $\mathrm{pH} 7.2$ added to equal volumes of blue sampling buffer solution were centrifuged at $10,000 \mathrm{~g}$ for five minutes at $5^{\circ} \mathrm{C}$ and cooled on ice after being boiled in water bath for 3 minutes; they were then stored at $-20^{\circ} \mathrm{C}$ for further experimentation. Ten $\mu 1$ aliquots of the samples were loaded on gels in six replicates. Coomasie Brilliant Blue R - 250 was used for staining. The various protein bands were identified after destaining and scanning. The bands that appeared in females' and not in males' lanes were identified as vitellogenin (Fleig 1997, Raikhel and Snigirevskaya 1998). Determination of varying amounts as percentage of vitellogenin in the vitellogenic $\mathrm{F}_{1} P$. truncatus haemolymph was carried out.

\section{Data Analysis}

Kruskal-Wallis tested the difference in vitellogenin levels among vitellogenic females reared on different maize varieties; the IS of varieties to $P$. truncatus as well as the weight losses among the maize varieties after insect infestation. Multiple Comparisons followed the analysis of variance. Relationships between vitellogenin levels and IS were tested (Gomez and Gomez 1984, Fowler et al. 1999).

\section{RESULTS}

Index of Susceptibility of the Maize Varieties

The mean number of $\mathrm{F}_{1} P$. truncatus from the different varieties varied from $36 \pm 0.89$ to $132 \pm 0.78$ and were in the order $\mathrm{ZM}$ 521 $>$ ZM 421 > ECAVL1-DLN > WEEVIL A $>$ LOCAL1> LOCAL 2 (Fig.1). The numbers from the six varieties were significantly different, $X^{2}=45.55,5 \mathrm{P}<$ 0.05. Multiple comparisons showed 
significant differences in the insect infestations between the different maize varieties at $\mathrm{P}<0.05$. The IS of maize varieties to $P$. truncatus, a function of emerged $F_{1}$ adult numbers and their median developmental periods were found to vary significantly $X^{2}=48.35, \mathrm{P}<0.05$. Variety ZM 521 exhibited the highest IS while the local variety, LOCAL 2 had the lowest IS (Table 1).

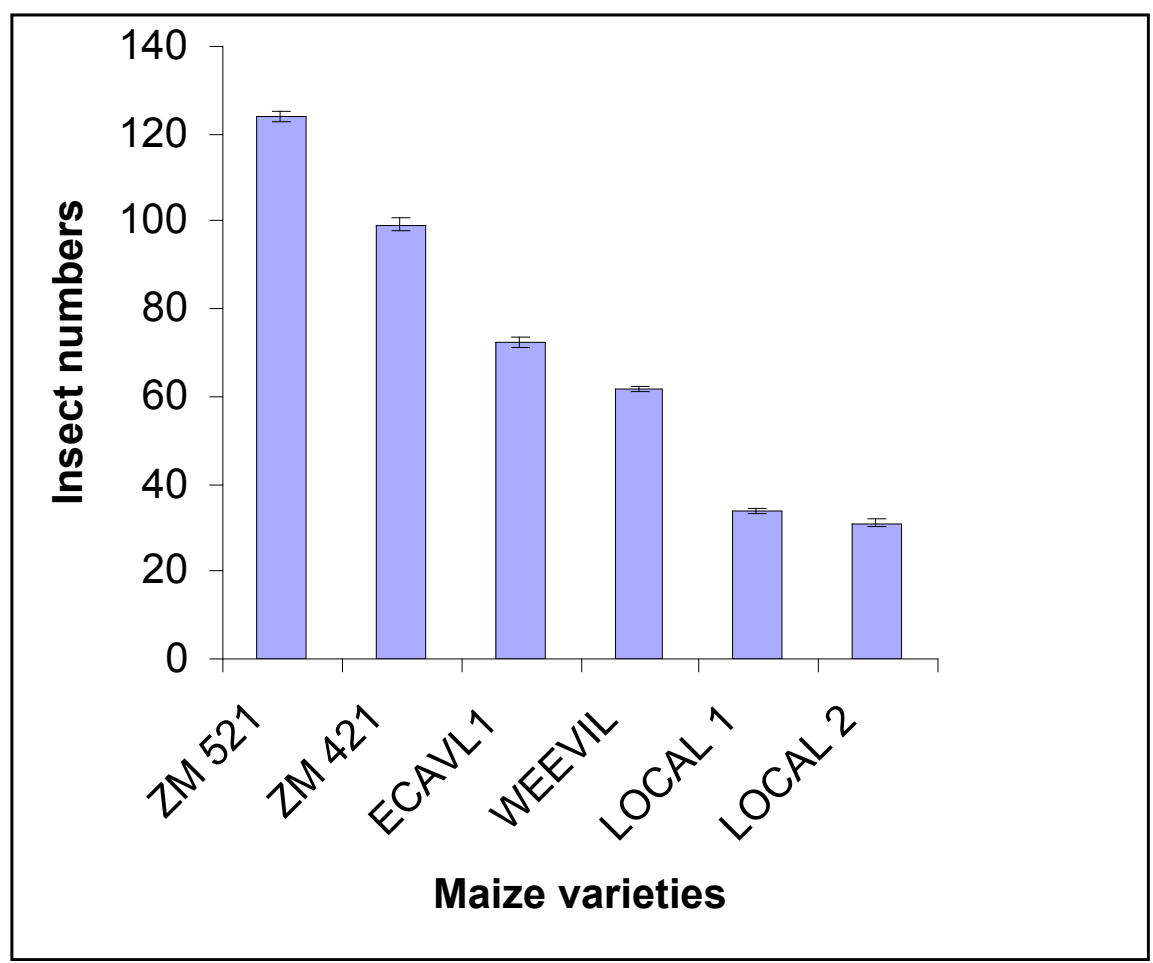

Figure 1: $\quad$. truncatus populations from the different maize varieties at $\mathrm{F}_{1}$

Table 1: $\quad$ Mean indices of susceptibility and weight losses (\%) of the maize varieties to $P$. truncates

\begin{tabular}{lcc}
\hline Variety & Index of Susceptibility & Weight Loss (\%) \\
\hline ZM 521 & $14.18 \pm 0.131$ & $14.75 \pm 0.007$ \\
ZM 421 & $12.47 \pm 0.214$ & $12.89 \pm 0.063$ \\
ECAVLI-DLN & $10.94 \pm 0.052$ & $9.50 \pm 0.004$ \\
WEEVIL A & $10.17 \pm 0.113$ & $8.65 \pm 0.032$ \\
LOCAL 1 & $8.21 \pm 0.065$ & $7.00 \pm 0.007$ \\
LOCAL 2 & $7.91 \pm 0.152$ & $6.89 \pm 0.001$ \\
\hline
\end{tabular}

Weight Losses of the Maize Varieties after Insect Infestations

After emergence of $\mathrm{F}_{1} P$. truncatus, the maize samples had lost weight in the following decreasing order ZM 521> ZM 421> ECAVL1-DLN > WEEVIL A > LOCAL $1>$ LOCAL 2 (Table 1). There was a significant difference among the weights 
lost by the varieties, $X^{2}=46.36$ at $\mathrm{P}<$ 0.01. Correlation test showed a positive relationship between weight losses and the IS of the varieties to $P$. truncatus, $\mathrm{r}=0.91$.

Vitellogenin Levels in Female $P$. truncatus Reared on Different Maize Varieties

Different percentage levels of haemolymph vitelogenin were exhibited by $F_{1}$ vitellogenic $P$. truncatus females which fed on the different maize varieties. The highest amount of vitellogenin was recorded in females raised on variety ZM 521 while the lowest was observed in insects from LOCALS 1 and 2. Mean percentages varied as shown in figure 2: ZM $521>$ ZM $421>$ ECAVL1-DLN > WEEVIL A > LOCAL 1 $>$ LOCAL 2. Kruskal-Wallis indicated a significant difference among vitellogenin levels at $\mathrm{P}<0.05$, 5. Multiple comparisons showed significant differences between vitellogenin means at $\mathrm{P}<0.05$. There was a positive correlation, $\mathrm{r}=0.96(\mathrm{P}<0.05)$ between vitellogenin percentages in $P$. truncatus haemolymph and the IS of the different maize varieties to $P$. truncatus.

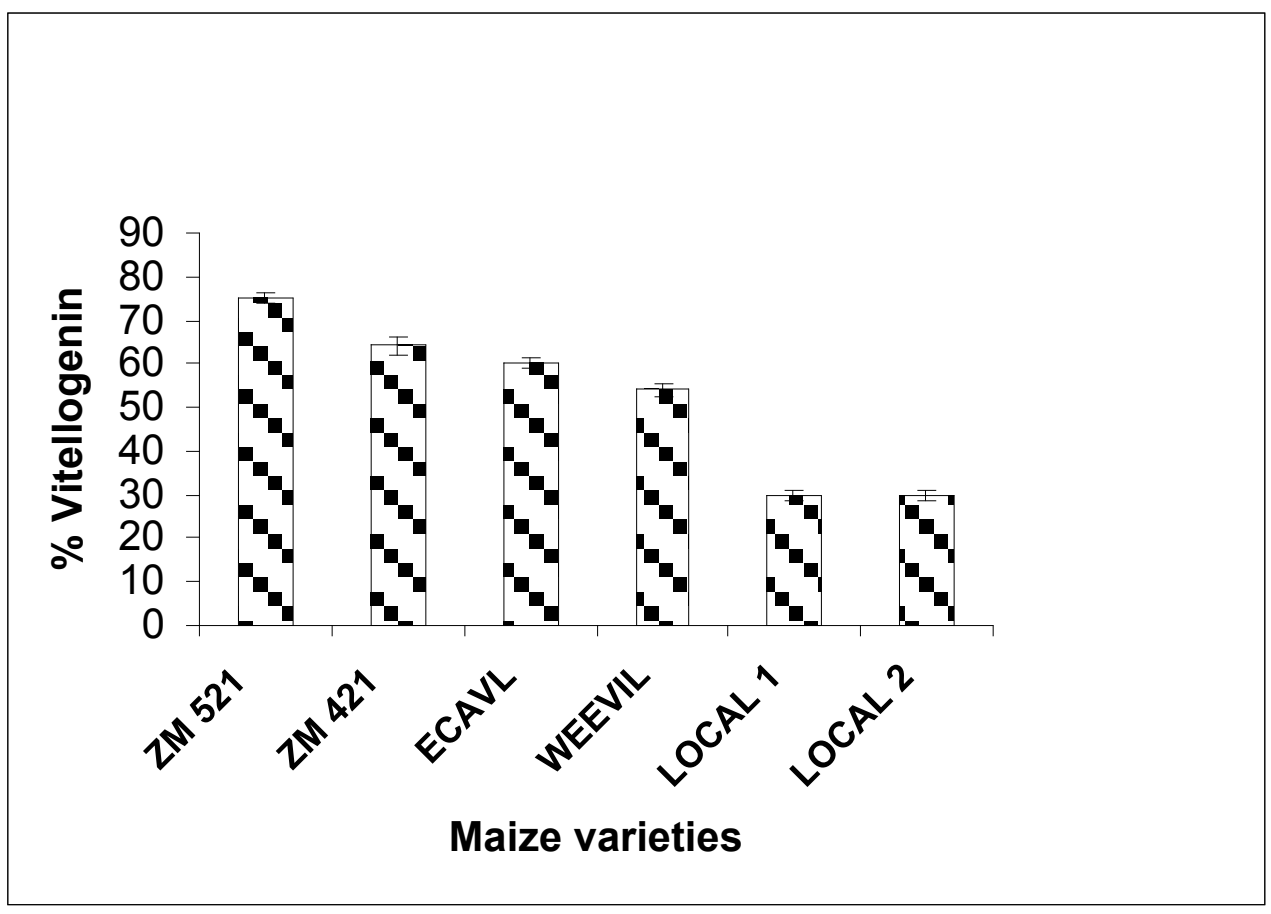

Figure 2: $\quad$ Amount of vitellogenin in Prostepanus truncatus females reared on different maize varieties

\section{DISCUSSION}

Effect of the maize varieties to $P$. truncatus was different as reflected by the IS of the maize varieties to the insect and the weight lost by the different varieties. The parameters were used to indicate the trend of varietal effect to the insect attack and correlated positively with the vitellogenin percentages in the tested insects.

\section{P. truncatus Infestations and Weight Losses of the Maize Varieties \\ Insect pest numbers from the varieties resulting in the varying IS corresponded}


positively with vitellogenin levels and weight losses of the different maize varieties to $P$. truncatus. The lowest number of $\mathrm{F}_{1} P$. truncatus from LOCAL 2, the longest developmental period of the insects in this variety as well as the least weight loss show that the variety has the lowest IS and hence the most resistant. Variety ZM 521 with the highest IS had most $\mathrm{F}_{1}$ individuals emerging within the shortest developmental period and lost the greatest weight. These results support observations by Dobie (1974) and Rugumamu (2005) who reported that susceptibilities of the maize varieties studied and other cereals to the cosmopolitan Sitophilus zeamais and $P$. truncatus attack were variable.

Prostephanus truncatus adults and larvae are serious pests as they cause damage culminating in great maize losses basically because of their relentless feeding habit, the presence of biting-crushing mandibles as well as their hypognathous type of head orientation (Chapman 1998, Hill 1987, van Emden 1999). The comparatively lower losses recorded in this study could be attributed to the fact that shelled maize is known to be relatively less attacked by $P$. truncatus and therefore recommended for storage (Hodges et al. 1983, Golob 1988, 2002).

\section{Haemolymph Vitellogenin Levels in $P$. truncatus Vitellogenic Females}

Adult females that fed on the different maize varieties had varying levels of vitellogenin in their haemolymph. Insects which were reared on ZM 521, the most infested variety had the greatest amount of vitellogenin in their haemolymph while those reared on the most resistant variety, LOCAL 2 had the lowest amounts of vitellogenin.

It is reported that the greater the amount of vitellogenin in an insect the greater the reproductive success of that insect feeding on a specific nutrient (Chapman 1998, Richards and Davies1977 and Rees1977). This fact can be explained by the amount of food available to the insect. It follows therefore that ZM 521 provided adequate nutrition in the shortest period to the insect pest for their vitellogenesis. Wheeler (1996) acknowledged that oogenesis is a nutrient limited process and that female insects are known to reproduce when richly provisioned with nutrients. It is further, acknowledged that the nutritional requirements of an insect affect growth, development and reproduction.

The findings with vitellogenin levels correspond positively with the trend of the indices of susceptibility of the maize varieties to $P$. truncatus and the weight losses. In this regard it is revealed that local maize varieties are more resistant than the improved varieties. It is, however, reported that there is a scarcity of local varieties of crops in Tanzania despite the information that about $90 \%$ of the seeds used by rural farmers are local varieties (Guardian 2006). Such a scarcity results in increased insect pest infestations and ultimately the local gene pool for the perpetuation/production of more resistant local varieties will no longer be available and hence a great setback to the smallholder farmers in this country. Given the $20 \%$ agricultural growth target by 2010 , (Guardian 2006) the stakeholders should access knowledge on seed storage and sustainability. The availability of local varieties could contribute to the local source of rural agricultural success.

\section{CONCLUSIONS}

On the basis of the findings, the effectiveness of $P$. truncatus management technology is revealed by employing the females haemolymph vitellogenin quantities as reflected by the IS and the weight losses of the different maize varieties to the pest. The vitellogenin parameter which is a measure of reproduction potential, ultimately serves to identify and select more resistant varieties of maize. Resistant varieties have best storage characters and hence play a great role in the on-farm storage 
pest management by reducing insect pest populations below economic injury levels.

The results corroborate that each maize variety exhibits a particular level of infestation by $P$. truncatus, the varying IS, amount of weight loss and these relate positively with quantities of haemolymph vitellogenin in $F_{1}$ vitellogenic females, an indicator of insect reproduction potential. It follows therefore that low indices of susceptibility of resistant varieties culminate to small quantities of vitellogenin in parent insect pests fed on the varieties.

For the foreseeable future, agriculture will continue to be the mainstay of the Tanzanian economy. Given that programmes for breeding crop varieties require enormous investment including time, it could be advisable that in the meantime, there should be collaboration of farmers, entomologists and Farmer Field School trainers (FFSt) through Agriculture Extension Services to minimize insect pest infestations by strengthening the cultivation and storage of the available resistant varieties of maize and other crops.

In the light of these informative results, further research is recommended in the search for more components for IPM at storage level such as testing efficacy of indigenous storage technologies in various regions in this country coupled with establishment of varying resistance of more maize varieties available to smallholder farmers.

\section{ACKNOWLEDGEMENTS}

The author is grateful to the Faculty of Science core support for funding part of the work, the Institute of Zoology, University of Dresden for technical assistance. Acknowledgement is also extended to Ilonga Agricultural Research Institute, smallholder farmers in Mkambarani and the agricultural extension staff whose cooperation made the research project possible.

\section{REFERENCES}

Abate T, van Huis A, Ampofo JKO 2000 Pest management strategies in traditional agriculture: An African perspective. Ann. Rev. of Entomol. 45: 631-659.

Aluja M, Diaz-Fleischer F, Papaja DR, Legunes G, Sirinski J 2001 Effect of age, diet, female density and host resource on egg load in Anastrepha ludens and Anastrepha oblique (Diptera: Tephritidae). J. Ins. Physiol. 47 (9): 975 - 988

Bhatia S K 1976. Resistance to Insects in stored grains. Trop. Stored Prod. Inf., 31: 21 - 35.

Borgemeister C 2001 Biology, Ecology and Biological Control of the Larger Grain Borer, Prostephanus truncatus, an exotic pest of Stored Maize and Cassava in Africa. The ESA 2001 Annual meeting. San Diego, CA. Dec. $9^{\text {th }} 2001$

Brewer JM, Pesce AJ and Ashworth, RB 1974 Experimental Techniques in Biochemistry. Prentice-Hall, Inc., Englewood Cliffs.

Chapman R F 1998 The insects: Structure and Function. London. $4^{\text {th }}$ Edn, Cambridge University Press, Cambridge.

Dent D 2000 Insect Pest Management. CABI International, Wallingford.

Dhliwayo T and Pixley KV 2003 Divergent Selection for Resistance to Maize Weevil in Six Maize Populations. Crop. Sci. 43: 2043 - 2049.

Dhliwayo T, Pixley KV and Kazembe V 2003 Combining Ability for Resistance Weevil Among 14 Southern African Maize Inbred Lines. Crop Sci. 45: $662-667$.

Dobie P 1974 The laboratory assessment of the inherent susceptibility of maize varieties to post-harvest infestation by Sitophilus zeamais (Motsch.) (Coleoptera: Curculionidae). J. Stored Prod. Res. 10 : 183 - 197. 
Elwells, H and Maas, A 1996 Natural pests and Disease Control. Natural Farming Network, Zimbabwe.

FAO 1991 Special programme for pest control in Africa. Plant protection services in Tanzania. A brief review and proposed structure for the 1990s. Rome.

Fleig R 1997 Laboratory Manual. Institute of Zoology, University of Dresden. (Mimeo)

Fowler J, Cohen L and Jarvis P 1999 Practical Statistics for Field Biology. John Wiley. New York.

Golob P 1988 Current status of the larger grain borer, Prostephanus truncatus (Horn) in Africa. Insect Science and its Application 96: 737-745.

Golob P 2002 Chemical, physical and cultural control of Prostephanus truncatus. Integrated Pest Management Reviews 7 (4): 245 - 271.

Gomez, A.K. and Gomez, A.A. 1984 Statistical Procedures for Agricultural Research. 2nd Edn .John Wiley and Sons. New York.

Guardian 2006 Twenty percent agricultural growth targeted by the year 2010. The Guardian IPP Media Ltd. Dar es Salaam, Tanzania. February $28^{\text {th }}$ : 2006.

Haines CP 1999 IPM for food storage in developing countries: $20^{\text {th }}$ century aspirations for the $21^{\text {st }}$ Century. Crop Pro. 19: 825 - 830 .

Hans-Jorg 1993 Yolk protein accumulation in Locusta migratoria (Orthoptera:Acrididae) Oocytes. Int. J. Ins. Morphol. Embryol. 22 Nos. 2 - 4.

Hill DS 1987 Agricultural Insects Pests of the Tropics and Their Control. CambridgeUniversity Press.

Hodges RJ, Dunstan WR, Magazini I and Golob P 1983. An outbreak of Prostephanus truncatus (Horn) (Coleoptera: Bostrichidae) in East Africa. Prot. Ecol. 5 : 183 - 194.

Kilimo/GTZ, 1996 Madawa ya Kilimo Matumizi, tahadhari na athari zake.
Tanzania-German Project for Integrated Pest Management.

Kostal V 1993 Oogenesis and oviposition in the cabbage root fly, Delia radicum (Diptera: Anthamyiidae) influenced by food quality, mating status and host plant deprivation. Eur. J. Entomol. 90: $137-147$.

Neuenschwender P, Borgemeister C, Landewald J 2003 Biological Control in IPM Systems in Africa. CABI Publishing, Wallingford.

PRA 1991 Participatory Rural Appraisal Handbook World Resources Institute.

Raikhel AS and Snigirevskaya ES 1998 Vitellogenesis. In: Microscopic Anatomy of Invertebrates. Volume IIC, Insecta.

Ravnborg HM 2004 Collective action in pest management. In Meinzen-Dick R.S. and Di Gregorio M. (Ed.). Collective Action and Property Rights for Sustainable Development.

Rees HH 1977 Insect Biochemistry. Chapman and Hall.

Richards OW and Davies RG 1977 IMMS' General Textbook of Entomology, Vol. 1. Structure, Physiology and Development, 10th Edn.. Methuen, London.

Rugumamu CP 2003 Insect infestation of maize, Zea mays (L.) in indigenous storage structures in Morogoro region, Tanzania. Tanz. J. Sci. 29: (No.2), 1 10.

Rugumamu CP 2005 Management of insect pest infestations on farm stored maize, Zea mays in Tanzania: A contribution to integrated pest management. Sida/SAREC Research Report, University of Dar Salaam.

Shires SW and McCarthy S 1976 A Character for sexing live adults of Prostephanus truncatus (Horn) (Coleoptera:Bostrichidae). J. Stored Prod. Res. 12: 273-5.

UNIDO 2004 Food is lost through poor storage. The Guardian. IPP Media Ltd. Dar es Salaam, Tanzania. November $30^{\text {th }}: 2004$. 
United Republic of Tanzania (URT) 2005 National Strategy for Growth and Reduction of Poverty (NSGRP). Vice President's Office, Dar es Salaam. van Emden HF 1999 Pest Control. Cambridge University Press.

Wheeler DE 1996 The role of nourishment in oogenesis. Ann. Rev. of Entomol.

41: $407-431$. 